\title{
O DIREITO DO TRABALHO NO ANO 2000*
}

\author{
Octávio Bueno Magano \\ Professor Titular do Departamento de Direito do Trabalho \\ da Faculdade de Direito da Universidade de São Paulo
}

Resumo:

O artigo principia com a análise de Edgard Morin sobre o ano 2000 , a sua simbologia dos números e a diferença que estabelece entre teoria e doutrina.

Em seguida trata da questão do modelo socialista e socialdemocrata e seus reflexos na nossa área trabalhista, no que concerne ao paternalismo e intervencionismo estatal da CLT, do corporativismo e do problema da composição paritária e do vocalato da Justiça do Trabalho, e também da necessidade de revisão do modelo de organização sindical e da seguridade social.

Quanto a esta última, examina o art. 194 da Constituição Federal que estabelece a sua organização, comentando as Leis n. 8.212/91, art. $3^{\circ}$ da Lei n. $7.787 / 89$, art. 22, I, da Lei n. 8.212/91, art. 195, I, da Lei Magna e de eventuais inconstitucionalidades desses diplomas legais, e em seguida a Lei n. 8.213/91, conhecida como Lei de Benefícios e a questão da substituição da aposentadoria por tempo de serviço.

Finaliza com a perspectiva de que a partir do ano 2000 deverá haver o recuo do intervencionismo estatal e os decorrentes reflexos na CLT, Justiça do Trabalho e Seguridade Social.

Abstract:

The article begins with the analysis of Edgard Morin on the year 2000, his symbology of numbers and the difference he establishes between theory and doctrine.

It goes on to treat of the question of the socialist and social democrat models and their reflexes on our labor area, in what refers to paternalism and state intervention in the CLT (the labor code), corporations and the problem of parity in composition and the lay judges of the labor courts and also of the need to revise the model of union organization and social security.

In what this last is concerned, the article examines section 194 of the Federal Constitution, that establishes its organization, commenting Laws \# 8.212/91, section 3rd of the Law \# 7.787/89, section 22, I, of Law

* São Paulo, 29 de setembro de 1992. 
\# 8.212/91, section 195 of the Constitution and the eventual lacks constitutionality of these statutes, examining then Law \# 8.213/91, known as the Benefits Law and the question of substitution of retirement for working time.

The article ends with the prospect of a diminishing of state intervention from the year 2000 and the reflexes of this in the CLT, Labor Courts and Social Security.

Como assinala Edgard Morin, o ano 2000 chama atenção pela sua magia decimal ambígua, com três zeros anunciando três vezes nada, ou, numa visão mais otimista, com três ovos, acenando para um universo completamente novo. 1

Ocorre-nos que os três zeros ou os três ovos são precedidos pelo número dois, indicativo de dualismo e, pois, de duas ordens de idéias irredutíveis.

A julgar pela simbologia dos números, o século dos 2000 será marcado pelo contraste entre os adeptos de novas teorias e os defensores de doutrinas falidas.

Segundo Morin, um sistema de idéias pode traduzir-se em teoria ou em doutrina. Enquanto teoria, apresentar-se-á como sistema aberto, incentivador de pesquisas, debates, diálogos, o que o sujeita tanto ao enriquecimento quanto à degradação. Enquanto doutrina, exteriorizar-se-á como auto-suficiente, frio, não alterável e aparentemente não biodegradável. ${ }^{2}$

$\mathrm{Na}$ área trabalhista, o último modelo, inspirado no socialismo e nas múltiplas variações da social democracia, produziu, entre nós, os seguintes fenômenos: o da proteção trabalhista, contida na CLT; o da implantação da Justiça do Trabalho; o da criação da Seguridade Social.

A concepção presente na elaboração da CLT foi paternalista, baseada no entendimento de que a questão social se soluciona através de intenso intervencionismo estatal. De acordo com tal diretriz, elaborou-se texto extremamente minucioso (quase mil artigos), com pouquíssimo espaço para a atuação da autonomia da vontade e a partir do pressuposto de que o empregador

\footnotetext{
1. Pour sortir du $X X^{o}$ siécle, Paris, Nathan, 1981, p. 84.

2. Ibid., p. 93 .
} 
estaria no permanente propósito de ilaquear a boa-fé do empregado, a fim de o explorar.

Dois preceitos do volumoso corpo de normas traduzem bem a filosofia que o inspirou: "art. $9^{\circ}$ - Serão nulos de pleno direito os atos praticados com objetivo de desvirtuar, impedir ou fraudar a aplicação dos preceitos contidos na presente Consolidação"; "art. 444 As relações contratuais de trabalho podem ser objeto de livre estipulação das partes interessadas em tudo quanto não contravenha às disposições de proteção ao trabalho, aos contratos coletivos que the sejam aplicáveis e às decisōes das autoridades competentes"

Ocupando o legislador o campo destinado ao entrelaçamento de relações trabalhistas, pouco espaço deixou à atuação dos sindicatos e ao desenvolvimento das convenções coletivas de trabalho.

Por outro lado, envenenou o relacionamento entre empregados e empregadores, ao partir do pressuposto de serem os últimos exploradores, quando, muitas vezes, estão voltados ao aprimoramento das aptidões dos primeiros, ao terem presente que o sucesso dos empreendimentos respectivos, freqüentemente, depende menos dos recursos materiais de que possam dispor do que dos recursos humanos, que se lhes ofereçam. De acordo com isso, refere-se Peter F. Drucker a uma evolução "from working by the sweat of our brow and by muscle to industrial work and finally to knowledge work". ${ }^{3}$

Por último, é preciso assinalar a relação de causa e efeito entre excesso de proteção e tendência à ampliação do mercado informal do trabalho, com o efeito colateral de incentivo à corrupção entre agentes da fiscalização.

No que concerne à Justiça do Trabalho, é mister considerar primeiro a sua magnitude e o enorme custo que representa para o erário. No entanto, sabe-se que as reclamações trabalhistas não se desatam antes de sete anos, o que constitui indicação clara de que o referido órgão do Poder Judiciário não está satisfazendo os objetivos visados com a sua criação.

Criou-se a Justiça do Trabalho, como se sabe, com a finalidade de que pudesse, a curtíssimo prazo, dar solução aos conflitos trabalhistas. No quadro do corporativismo, vigorante ao tempo em que foi instituída, o que se procurava evitar eram os movimentos autônomos dos grupos profissionais e 
econômicos, componentes da sociedade civil. Desestimularam-se, em conseqüência, os procedimentos de autocomposição e proibiram-se terminantemente a greve e o lock-out como recursos anti-sociais. Para preencher o vácuo, criou-se, então, a Justiça do Trabalho com a incumbência de dirimir todos os conflitos trabalhistas, tanto individuais quanto coletivos. E, porque se tratava de criação de origem corporativista, nasceu com o timbre respectivo, compondo-se não apenas de bacharéis em Direito mas também de vogais representantes, respectivamente, de empregados e de empregadores.

Vale a pena transcrever aqui as causas alinhadas por Salete Maria Polita Marcaloz para explicar a apontada composição paritária: "Os fundamentos da composição paritária prendem-se à necessidade de organização de uma justiça especial que concretizasse a ideologia corporativa. Para tanto, a presença das classes econômicas, patrão e empregado, era simbolicamente a representaçāo da harmonia a legitimar essa estrutura. Era o comprometimento das classes com o resultado final da atuação jurisdicional, na realidade, produzida só pelo Estado, uma vez que este construiu o sindicalismo sob um modelo só seu e condicionou a ação dos tribunais à observância da lei, elaborada, também, apenas por ele. Assim a representação classista tem uma fundamentação por demais relevante: legitimar, com sua presença, o intervencionismo estatal, como forma de dificultar ou suprimir as reivindicaçōes sociais dos trabalhadores, uma vez que eles participam de uma tarefa inerente e exclusiva do Estado; e submeter, também, certas parcelas empresariais, principalmente os empregadores de pequeno porte". 4

$O$ apontado modelo de organização sindical precisa ser revisto, para perder o ranço de sua origem corporativista. A eliminação do vocalato possibilitaria a duplicação do número de juízes trabalhistas sem aumento da despesa pública.

Falta, agora, considerar a Seguridade Social. Como lembra Tupinambá Miguel Castro do Nascimento, seguridade social "não é sinônimo de seguro social ou previdência social; é ampla em sua abrangência. Em primeiro lugar, na seguridade social a tutela é ilimitada, porque alcança todo ser humano, pelo simples fato de existir e viver. Não só os beneficiários mas todos os residentes do país, trabalhadores ou não, empresários ou não. Em segundo lugar, o que vai 
interessar não é mais o risco social; sim a carga social ou, como diz Francisco de Ferrari, 'todos los estados de necesidad de sus miembros, cualquiera que fuera su origem y naturaleza'. Em terceiro lugar, a responsabilidade pelo sistema de seguridade social é da coletividade em geral, do próprio Estado". 5

$\mathrm{Na}$ Constituição de 1988, foi a seguridade concebida com extrema largueza, tal como se os constituintes, que a esculpiram, estivessem imbuídos do desejo de, como diria Pierre Rosanvallon, "substituer à l' incertitude de la providence religieuse la certitude de la providence étatique". ${ }^{6}$ Enquanto isso se dava no Brasil, na grande maioria dos países do mundo ocidental abundavam críticas contundentes ao Estado do Bem-Estar Social, verificando-se claro afastamento desse modelo por parte dos Estados Unidos da América do Norte ("reaganismo") e da Inglaterra ("tatcherismo"). Na Alemanha Ocidental, na França, na Itália, na Espanha e em Portugal, embora não se houvesse cunhado nenhuma expressão para significar o paulatino afastamento de tais países do referido modelo, é inquestionável haver elè ocorrido. Não obstante, no Brasil, deu-se exatamente o contrário. Nossos constituintes, sob a influência dominante de um estatismo arestoso e desatualizado, em plena fase de recesso mundial do "welfarismo", armaram o mais rebuscado modelo de Estado do Bem-Estar Social.

Em conformidade com a apontada visão, integram a seguridade social, a previdência social, na dimensão que sempre possuiu entre nós, mais os segmentos da saúde e da assistência social.

Nos termos do art. 194, da Constituição, a organização da Seguridade Social deve subordinar-se aos seguintes princípios: universalidade da cobertura e do atendimento; uniformidade e equivalência dos benefícios e serviços às populações urbanas e rurais; seletividade e distributividade na prestação dos benefícios e serviços; irredutibilidade do valor dos benefícios; eqüidade na forma de participação no custeio; diversidade da base de financiamento e caráter democrático e descentralizado da gestão administrativa,

5. A ordem social e a nova Constituição, Rio de Janeiro, 1991, p. 12.

6. La crise de l'État providence, Paris, Seuil, 1981, p. 28. 
com a participação da comunidade, em especial de trabalhadores, empresários e aposentados.

Tendo em vista tais diretrizes, o legislador ordinário editou as Leis ns. 8.212/91 e 8.213/91.

O primeiro diploma legal citado, composto de mais de cem artigos, aparece sob a rubrica de lei de custeio e nele se indicam realmente as fontes de custeio da Seguridade Social. Antes, porém, delineiam-se os traços característicos de cada um dos segmentos que a compõem. Importante é o tópico relativo à sua organização, merecendo ser aqui transcrito o preceito regulador da estrutura do Conselho Nacional da Seguridade Social: "art. $6^{0}$ - Fica instituído o Conselho Nacional da Seguridade Social, óngão superior de deliberação colegiada, com a participação da União, dos Estados, do Distrito Federal, dos Municípios e de representantes da sociedade civil. \$ $1^{\circ}$ - O Conselho Nacional de Seguridade Social terá 15 (quinze) membros e respectivos suplentes, sendo: a) 4 (quatro) representantes do Governo Federal, dentre os quais, 1 (um) da área de saúde, 1 (um) da área de previdência social e 1 (um) da área de assistência social; b) 1 (um) representante dos governos estaduais e 1 (um) da prefeituras municipais; c) 6 (seis) representantes da sociedade civil, sendo 3 (três) trabalhadores, dos quais pelo menos 1 (um) aposentado e 3 (três) empresários; d) 3 (três) representantes dos conselhos setoriais, sendo um de cada área da Seguridade Social, conforme disposto no Regimento do Conselho Nacional da Seguridade Social (...)"

O Conselho, acima estruturado, ficou investido das seguintes funções: "art. $7^{Q}$ - Compete ao Conselho Nacional da Seguridade Social: I estabelecer as diretrizes gerais e as políticas de integração entre as áreas, observado o disposto no inciso VII do artigo 194 da Constituição Federal; II - acompanhar e avaliar a gestão econômica, financeira e social dos recursos e o desempenho dos programas realizados exigindo prestação de contas; III - apreciar e aprovar os termos dos convênios firmados entre a seguridade social e a rede bancária para a prestação dos servisos; IV - aprovar e submeter ao Presidente da.República os programas anuais e p.'urianuais da Seguridade Social; $V$ aprovar e submeter ao Órgão Central do Sistema de Planejamento Federal e de Orçamentos a proposta orçamentária anual da Seguridade Social; $И$ - estudar, debater e aprovar proposta periódica dos valores dos benefícios e dos salários-de-contribuição, a fim de garantir, de forma permanente, a preservação de seus valores reais; VII - zelar pelo 
fiel cumprimento do disposto nesta Lei e na legislação que rege a Seguridade Social, assim como pelo cumprimento de suas deliberaçōes; VIII - divulgar, através do Diário Oficial da Uniāo, todas as suas deliberações; XI - elaborar o seu regimento interno"

Quanto ao financiamento da Seguridade Social, prevalecem as seguintes regras: "art. 11 - No âmbito federal, o orçamento da Seguridade Social é composto das seguintes receitas: I - receitas da União; II - receitas das contribuiçōes sociais; III receitas de outras fontes. Parágrafo único Constituem contribuições sociais: a) as das empresas, incidentes sobre a remuneraçāo paga ou creditada aos segurados a seu serviço; b) a dos empregadores domésticos; c) as dos trabalhadores, incidentes sobre o seu salário-de-contribuição; d) as das empresas, incidentes sobre faturamento e lucro; e) as incidentes sobre a receita de concursos de prognósticos"

Cumpre, nesta altura, assinalar a inconstitucionalidade do preceito em que se aponta como base de incidência da contribuição a cargo das empresas "a remuneração paga ou creditada aos segurados a seu serviço".

A inconstitucionalidade em causa se apura mediante a simples constatação de que o termo empregadores e o vocábulo salários, constantes do art. 195, I, da Lei Magna, rechaçam, de modo inequívoco, a possibilidade de se exigirem contribuições sobre pagamentos efetuados a diretores, trabalhadores avulsos e autônomos. Com efeito, a palavra empregadores tem como correlata a expressão empregados. E salário é pagamento que só se faz a empregados; a diretores pagam-se honorários, denominando-se remuneração o estipêndio de avulsos e autônomos.

Essa interpretação, de índole gramatical ou filológica, dificilmente pode ser superada po: outra, de diversa natureza, porque, como acentua Manuel A. Domingues de Andracie. "as palavras da lei são às vezes tāo explícitas e categóricas que não podem exprimir, nem sequer de modo imperfeito ou constrangido, mais do que um só pensamento. Em tal caso, o intérprete deve resignar-se a aceitar o sentido verbal da lei..." 7

Tudo indica que o constituinte de 1988, ao usar da expressão folha de salários e não, por exemplo - folha de pagamentos -, visou limitar 
contribuição de efeitos perniciosos sobre o mercado de trabalho, de vez que castiga o empregador, com grande contingente de mão-de-obra, incentivando, em conseqüência, a expansão do trabalho clandestino.

A despeito da flagrante inconstitucionalidade do art. $3^{2}$, da Lei $\mathbf{n}$. 7.787/89, e do art. 22, I, da Lei n. 8.212/91, tem sido ela, por vezes, negada, sob a alegação de ser já tradicional a alusão a salários para significar pagamentos efetuados a pessoas sem relação empregatícia.

Sucede que a expressão salário-de-contribuiçāo, realmente tradicional na sistemática previdenciária, não guarda paralelismo com o termo salário.

É comum, aliás, que os substantivos compostos possuam significado diverso de cada um dos vocábulos que os compõem, como ocorre, por exemplo, com banana-prata, couve-flor, salário-familia.

Ninguém imaginaria enxergar prata no primeiro, flor no segundo e natureza salarial no terceiro. Da mesma maneira, há de ser repudiada a idéia de que, na locução salário-de-contribuição, já estivesse presente o conceito de salário. E, por isso mesmo, era curial admitir-se poder ela, no passado, abarcar remunerações não exclusivamente de empregados mas igualmente de diretores, sócios, trabalhadores avulsos e autônomos.

Tal abrangência tornou-se, no entanto, incompatível com a linguagem estrita da Constituição de 1988. Como ensina Jorge Miranda, " $a$ superveniência de nova Constituição acarreta 'ipso facto', pela própria função e força desta, o desaparecimento do direito ordinário anterior com ela desconforme" ${ }^{\prime \prime}$

A Lei n. 8.213/91 exterioriza-se sob a rubrica de Lei de Benefícios, compondo-se de mais de cento e cinqüenta artigos.

Os benefícios por ela prodigalizados são os referidos em seu art. 18, pelo modo seguinte: "O Regime Geral de Previdência Social compreende as seguintes prestações, devidas inclusive em razäo de eventos decorrentes de acidente do trabalho, expressas em beneficios e serviços: I - quanto ao segurado: a) aposentadoria por invalidez; b) aposentadoria por idade; c) aposentadoria por tempo de serviço; d) aposentadoria especial; e) auxílio-doença; f) salário-família;

8. Manual de direito constitucional, Coimbra, Coimbra, 1983, t. II, p. 248. 
g) salário-matemidade; $h$ ) auxilio-acidente; i) abono de permanência em serviço; II quanto ao dependente: a) pensão por morte; b) auxílio-reclusão; III - quanto ao segurado e dependente: a) pecúlios; b) serviço social; c) reabilitação profissional"

Do próprio conceito de Previdência Social, instituição distribuidora de renda, quando esteja esta diminuída ou extinta, em virtude de contingência social (doença, velhice, acidente, etc), tira-se a ilação de que a inserção, no seu âmbito, da aposentadoria por tempo de serviço constitui extravagância. Sendo esta a prestação mais dispendiosa do sistema, não resulta, todavia, de nenhuma contingência apta a extinguir ou diminuir a renda do trabalhador. Ao contrário, sabendo-se que, até recentemente, o ingresso no mercado de trabalho se dava a partir dos doze anos, tem-se que respectivamente aos 37 e aos 42 anos, mulheres e homens, no pleno vigor de suas forças, poderão se aposentar. Ora, num país pobre como o Brasil, que precisa fazer seleção de recursos para atender a mil e tantas misérias, o menos que se pode dizer do tratamento dado à aposentadoria por tempo de serviço é que se apresenta extravagante. Quando timbrassem os legisladores em não a excluir do rol das prestações previdenciárias, seria medida de elementar cautela que se introduzisse, no sistema, um dado de moderação, qual, por exemplo, o da idade mínima de 55 anos.

Não se oponha à preconizada extinção da aposentadoria por tempo de serviço o argumento de que representaria ela agressão à expectativa natural das pessoas de trabalharem no presente para repousarem no futuro. Tal tendência não é por certo passível de censura. Ao contrário, há de ser mesmo incentivada, como encorajados hão de ser todos os tipos de seguro: o de vida; o de acidentes; o contra fogo; o contra furto e até o seguro contra mal tempo, em período de férias, que vem sendo cada vez mais praticado em alguns países europeus. Mas todos esses casos pertencem ao âmbito do seguro privado, não podendo nenhum deles inserir-se na esfera da Previdência Social.

O terreno ideal para o florescimento da aposentadoria por tempo de serviço é o da previdência privada. Na área da Previdência Social, apresentase como corpo estranho e prejudicial ao adequado funcionamento do sistema.

Nem se venha com o argumento da reduzida expectativa de vida do trabalhador brasileiro, principalmente no norte e no nordeste do país. Tal argumento se mostra falacioso, porque o indicado dado da realidade não aponta para a necessidade de se manter a aposentadoria por tempo de serviço e sim 
para a conveniência de se preverem limites de idade diversos para a aposentadoria, conforme a região geográfica do país (65 no sul, 50 no norte, por exemplo).

Ao contrário do modelo doutrinário acima transcrito, o que há de prevalecer, a partir do ano 2000, será o recuo do intervencionismo estatal, substituindo-se a Consolidação das Leis do Trabalho pelas cláusulas constantes das convenções coletivas do trabalho. Mostra-se tal modelo melhor do que o atual, porque reflete, com precisão, o ponto de equilíbrio entre os interesses conflitantes dos parceiros sociais, o que implica melhor adaptação entre norma e realidade, diminuição de custos e constrição do mercado informal de trabalho. Como assinala Chouraqui, "c'est surtout à un développement de la négociation collective qu'a conduit la conviction, largement partagée, que la régulation étatique est plus adaptée à une 'guerre de positions' qu'a une moderne 'guerre de mouvement', correspondant à l'évolution rapide des contextes et des intérêts dont la confrontation mérite donc d'être régulée autrement".

Ao invés da tutela, desenvolvida pela Justiça do Trabalho, com enormes custos para a sociedade e reduzidíssima eficiência, segundo se depreende da demora na solução dos conflitos perante ela ajuizados, o que se preconiza é a utilização crescente dos mecanismos de autocomposição, como conciliação, mediação e arbitragem.

No que toca à Seguridade Social, o de que há mister é baldar-se a mania de grandeza e engendrarem-se mecanismos de proteção social consentâneos com nossas possibilidades. A primeira providência, nesse sentido, consiste no estímulo à atividade econômica, com a diminuição dos pesados tributos que recaem sobre as empresas (o aumento da riqueza é o melhor antídoto contra o estado de necessidade); a segunda traduz-se na diminuição do tamanho das entidades estatais de proteção social, atribuindo-se-lhes apenas a incumbência de satisfazer, até limites razoáveis, riscos sociais da população mais carente; a terceira cautela cifra-se na estadualização da previdência, em conformidade, aliás, com o disposto no art. 23 , XII e art. $24, \S 1$, da

9. Alain Chouraqui, Quelques difficultés actuelles d'articulation du juridique et du social, in Normes juridiques et régulation sociale, dirigido por Chazel F. e Commaile, J., Paris, LGDJ, 1991, p. 295. 
Constituição; a quarta medida corresponde à necessidade de transferir para o setor privado as principais modalidades de seguro social; a quinta e última resume-se na conveniência de se incentivarem outros métodos de proteção social, como o da mutualidade, o das associações privadas de assistência e o da família, todos fundados em solidariedade genuína e não no mecanismo frio de prestações oriundas da Previdência Social.

BIBLIOGRAFIA

ANDRADE, Manuel A. Domingues. Ensaio sobre a teoria da interpretaçāo das leis. Coimbra : Armênio Amado, 1978.

CHOURAQUI, Alain. Quelques difficultés actuelles d'articulation du juridique et du social, in Normes juridiques et régulation sociale, dirigido por Chazel F. e Commaille J. Paris : LGDJ, 1991.

DE FERRARI, Francisco. A ordem social e a nova Constituiçāo. Rio de Janeiro : Aide, 1991.

DRUCKER, Peter F. The new realities. New York : Harper e Row, 1989.

MARCALOZ, Salete Maria Polita. Representação classista na Justiça do Trabalho. Rio de Janeiro : Forense, 1984.

MIRANDA, Jorge. Manual de direito constitucional. Coimbra : Coimbra, 1983.

MORIN, Edgard. Pour sourtir du XX siècle. Paris : Nathan, 1981.

ROSANVALlon, Pierre. La crise de l'État providence. Paris : Sevil, 1981. 